\section{Even in the remote South Pacific, fish are eating plastic - and so are the people who eat those fish}

Plastics are universally associated with pollutants. Chemicals like bisphenol-A (BPA) and phthalates are commonly bonded to plastics during manufacturing. Polychlorinated biphenyls (PCBs) and other persistent organic pollutants (POPs) often adsorb onto plastics from surrounding waters when they are released into the ocean. Fish have been shown to ingest plastic and integrate these adsorbed pollutants into their tissues. Since fish are commonly served for human consumption, there are potential risks to human health and development from eating contaminated fish.

While research shows that in both Indonesia and the United States, $25 \%$ of fish sold for human consumption have man-made debris in their guts, there is no such data available for the South Pacific islands. On average, residents of the South Pacific consume fish products at a rate more than six times greater per year than their counterparts based in the Americas. Because of this, South Pacific Islanders are at potential greater risk for plastic pollutant absorption. As such, the authors sampled the gut contents of 126 fish destined for human consumption on Henderson Island, Lord Howe, and French Polynesia to document how much plastic these fish had recently eaten.

One-quarter of sampled species contained plastic fragments in their guts, as did $7.9 \%$ of individual fish. All plastic debris found were categorized as microplastics (under $5 \mathrm{~mm}$ in size) except for one $2 \mathrm{~cm}$-long synthetic rope, likely from a boat. The most common color of plastic found was blue ( $40 \%$ of the total items) followed by white $(30 \%)$, black $(20 \%)$, and green $(10 \%)$ which could indicate that fish preferentially consume certain colors of plastic. Factors like trophic level, feeding location, and fish length were found to have no significant relationship that could predict plastic ingestion.

The results show plastics are being consumed on a regular basis by residents of the South Pacific, even in these remote locations. Importantly, the authors note: "While many species are gutted prior to consumption, there are still potential negative health impacts due to pollutants introduced to the fish tissue by plastic ingestion. Additionally, in some island locations smaller fish are eaten whole and not gutted." The authors received no formal funding for this small study, so funding agencies could greatly improve the scope of this research by funding future activities.
This is a summary of: Ingestion of plastic by fish destined for human consumption in remote South Pacific islands

Accessible at: https://marxiv.org/y95vb

Authors: Alice Forrest, Mark Hindell

Added to MarXiv: April 2018

Published: Australian Journal of Maritime \& Ocean Affairs, 2018

Suggested Citation: Even in the remote South Pacific, fish are eating plastic - and so are the people who eat those fish. OCTO (2018). DOI: 10.31230/osf.io/zbhmg

See more MarXiv summaries at https://www.marxivinfo.org/ summaries

Join the MarXiv Summaries monthly newsletter at https:// oct.to/marxivsum

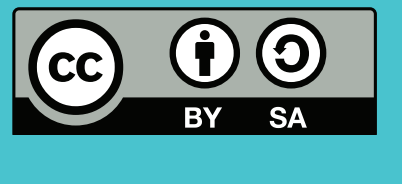

MarXiv is an ОСТO Initiative
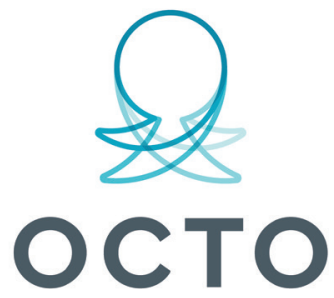

OPEN COMMUNICATIONS FOR THE OCEAN 